\title{
Can Copper-Coated Surfaces Prevent Healthcare-Associated Infections?
}

\author{
David J. Weber, MD, MPH; ${ }^{1,2}$ Jonathan A. Otter, $\mathrm{PhD} ;{ }^{3}$ William A. Rutala, PhD, MPH ${ }^{1,2}$
}

(See the article by Souli et al, on pages 765-771.)

Despite dramatic decreases in the incidence of healthcareassociated infections (HAIs) in recent years, a large prevalence study of US acute-care hospitals estimated that $\sim 722,000$ HAIs occurred in 2011, resulting in $\sim 75,000$ deaths. ${ }^{1}$ Several decades ago, Weinstein ${ }^{2}$ theorized that pathogens causing HAIs in the intensive care unit (ICU) had several sources: the patients' endogenous flora $(40 \%-60 \%)$, cross-infection via the hands of healthcare personnel (HCP; 20\%-40\%), antibiotic-driven changes in flora $(20 \%-25 \%)$, and other causes (including contamination of the environment; 20\%). ${ }^{2}$ More recently, accumulating scientific evidence has indicated that contamination of environmental surfaces in hospital rooms plays an important role in the transmission of several key healthcareassociated pathogens, including methicillin-resistant Staphylococcus aureus (MRSA), vancomycin-resistant Enterococcus spp (VRE), Clostridium difficile, Acinetobacter spp, and norovirus. ${ }^{3-6}$ In general, all of these pathogens share the following characteristics: ability to survive for prolonged periods of time on environmental surfaces, ability to remain virulent after environmental exposure, frequent contamination of the hospital environment, ability to colonize patients, ability to contaminate or transiently colonize the hands of HCP, and transmission via the contaminated hands of HCP. ${ }^{3-6}$ Evidence supporting the role of contaminated surfaces in the transmission of key healthcareassociated pathogens includes the following observations. (1) The surfaces in rooms of colonized or infected patients are frequently contaminated with the pathogen. ${ }^{3-6}$ (2) Contact with hospital-room surfaces or medical equipment by HCP frequently leads to contamination of hands and/or gloves. ${ }^{6}$ (3) The patient admitted to a room previously occupied by a patient colonized or infected with a pathogen (eg, MRSA, VRE, C. difficile, Acinetobacter) has a substantially increased likelihood (ie, 39\%$353 \%$ ) of developing colonization or infection with that pathogen. ${ }^{6}$ (4) Improved terminal cleaning of rooms decreases environmental pathogens ${ }^{7}$ and the rate of individual patient colonization and/or infections; it also leads to a decreased facility-wide rate of colonization and/or infection. ${ }^{8}$
Unfortunately, inadequate terminal room disinfection is common. ${ }^{7}$ In fact, studies have demonstrated that $<50 \%$ of room surfaces are cleaned. ${ }^{7}$ Therefore, and not surprisingly, many room surfaces remain contaminated with a multidrugresistant organisms (MDROs) following terminal room disinfection. ${ }^{5,6}$ Although enhanced education of environmental service staff with feedback regarding cleaning effectiveness (eg, fluorescent dye) improves cleaning effectiveness, overall cleaning remains suboptimal. ${ }^{7}$ For this reason, "no-touch" methods of terminal room disinfection have been developed. ${ }^{9-14}$ No-touch methods that use ultraviolet (UV) light devices or hydrogen peroxide systems for terminal room disinfection when the occupant has been colonized or infected with a MDRO have been demonstrated to reduce the risk of the subsequent room occupant developing colonization and/ or an HAI. ${ }^{11,13}$ Importantly, some studies have demonstrated a facility-wide reduction of HAIs ${ }^{15,16}$; furthermore, these reductions were not related to improved hand hygiene or to environmental cleaning compliance. ${ }^{17,18}$

One of the limitations of currently available UV devices or hydrogen peroxide systems is that they can only be used for terminal disinfection because patients and HCP must evacuate the room prior to use. Because daily room disinfection has been shown to reduce contamination of HCP hands and gloves, ${ }^{19}$ there has been interest in developing "no-touch" methods for decreasing MDRO surface contamination on a continuous basis. ${ }^{9}$ Such methods have been reviewed and include self-disinfecting surfaces using heavy metals, lightactivated photosensitizers, high-intensity narrow-spectrum light, low-dose continuous hydrogen peroxide, photocatalytic disinfection, bacteriophage-modified surfaces, and altered surface topography. ${ }^{12,14,20-22}$ Of these potential methods, the best studied is the use of heavy metals (eg, silver, copper) with copper-coated or impregnated surfaces; it is the only method that has been assessed in clinical trials. ${ }^{20-22}$

The studies assessing the effectiveness of no-touch methods including self-disinfecting surfaces for disinfection of room surfaces in hospitals can be divided into 3 general approaches.

Affiliations: 1. Department of Hospital Epidemiology, University of North Carolina Hospitals, Chapel Hill, North Carolina, United States; 2. Division of Infectious Diseases, University of North Carolina School of Medicine, Chapel Hill, North Carolina, United States; 3. Imperial College London Health Protection Research Unit in Healthcare Associated Infections and Antimicrobial Resistance, and Imperial College Healthcare National Health Service Trust, Infection Prevention and Control, London, United Kingdom.

Received April 5, 2017; accepted April 9, 2017

DOI: $10.1017 /$ ice.2017.90 
(1) the effectiveness of the self-disinfecting surface to kill or inhibit microbes artificially placed on the self-disinfecting surface, (2) the level of contamination on self-disinfecting surfaces in actual patient rooms compared to a "control" surface and (3) most importantly, clinical trials of a self-disinfecting surface to reduce HAIs.

Copper is an essential trace element in most living organisms, and $>30$ types of copper-containing proteins have been described. ${ }^{20}$ The use of copper by humans dates back to the fifth and sixth millennia $\mathrm{BC}^{23}$ Ancient civilizations used copper or copper compounds to prevent the growth of barnacles on the hulls of ships and as a medicinal agent. ${ }^{20}$ In the 19th and 20th centuries, inorganic copper preparations were used to treat chronic adenitis, eczema, impetigo, tuberculous infections, and syphilis. ${ }^{23}$ The cause of bacterial cell death to exposure to copper may relate to its ability to accept and donate single electrons leading to the generation of reactive oxygen species, resulting is cell lysis. ${ }^{14,20,21,23}$ In healthcare facilities, the most well-studied use of copper has been as a "self-disinfecting" surface, but many other uses have been studied, including copper-containing paints, fabrics, hand rubs, microfiber cleaning cloths, pens, and fins within air-conditioning units. ${ }^{20}$

Multiple studies have assessed the contact killing of microbes by copper surfaces. ${ }^{23}$ Contact with copper has been demonstrated to kill a variety of healthcare-associated pathogens including Staphylococcus aureus (including methicillinresistant S. aureus), Enterococcus spp, Escherichia coli, Klebsiella pneumoniae, Acinetobacter baumannii, Pseudomonas aeruginosa, and Mycobacterium tuberculosis. ${ }^{20}$ In general, contact killing of vegetative bacteria and fungi occurs rapidly with $>6-\log _{10}$ inactivation per hour. Spores (eg, C. difficile) are inactivated more slowly, but $>3-\log _{10}$ are inactivated within 24 hours. $^{23,24}$

In this issue of Infection Control and Hospital Epidemiology, Souli et $\mathrm{al}^{25}$ report on the frequency and level of contamination of multiple copper-coated surfaces (ie, patient beds, side table, IV pole, side cart handles, and manual antiseptic dispenser) compared to control surfaces in a patient room in an intensive care unit. ${ }^{25}$ The study was performed in a Greek ICU setting in which evidence showed that the environment was considerably more contaminated than other settings and where highly resistant organisms predominated. For example, $62 \%$ of $\mathrm{K}$. pneumoniae isolated from the environment were resistant to carbapenems and $100 \%$ were multidrug resistant; similarly, $98 \%$ of $A$. baumannii were resistant to carbapenems and $99 \%$ were multidrug resistant. Their study was conducted in 2 phases: In phase 1, enhanced environmental sampling was performed to identify the most microbiologically contaminated items to 'copperize'; this targeted use of copper items is an important strength of the study. Phase 2 was the intervention phase; in phase $2 \mathrm{a}$, copper-coated objects were placed next to uncoated objects (controls); and in phase $2 \mathrm{~b}$, cooper-coated objects were all placed in a single ICU compartment and non-copper-coated objects were placed in a different ICU compartment (controls). Combining the data for phases $2 \mathrm{a}$ and $2 \mathrm{~b}$ revealed that copper-coated surfaces were less likely to be microbially contaminated (ie, $55.6 \%$ vs $72.5 \%$ for controls, $P<.0001)$. Copper-coated surfaces were significantly less likely to be contaminated with gram-negative bacilli or Enterococcus spp, but no statistical reduction for A. baumannii, K. pneumoniae, or $S$. aureus was observed. Overall, the level of contamination was reduced by $\sim 0.7-\log _{10}$ $(P=.049)$. Importantly, no significant reduction was observed in phase 2a, in which copper items were placed next to uncoated objects, suggesting a possible interaction between the number of copper items and the level of reduction, which requires further investigation. The statistical approach used did not take into account the full range of variables; most importantly, indicators of hand-hygiene compliance and patient-level variables could have been included in a model with copper items as a separate variable. Souli et al reported no difference in hand-hygiene compliance during the study, but the effectiveness of environmental clean/disinfection was not assessed. Other limitations include the use of alcohol spray for daily disinfection of surfaces, which is an unusual approach and may limit the generalizability of the study; lack of randomization of patients to beds with copper items; and the lack of clinical and cost-effectiveness outcomes.

Multiple studies of copper-coated surfaces or devices have been conducted in the healthcare setting comparing the level and frequency of surface contamination to control surfaces (for a review of studies, see Weber and Rutala, ${ }^{20}$ Humphreys, ${ }^{21}$ Muller et $\mathrm{al}^{22}$ Weaver et $\mathrm{al}^{24}$ and O'Gorman and Humphreys $\left.^{26}\right)$. Studies have either used concurrent non-coppercoated control surfaces or a crossover design. Muller et $\mathrm{al}^{22}$ reported that 5 of 7 copper studies of copper-coated surfaces or fabrics reviewed demonstrated a significant reduction in quantitative bacterial contamination of $<1-\log _{10}$ (range, $<1-\log _{10}$ to $\left.2-\log _{10}\right)$. Limitations of the studies noted by Muller et $\mathrm{al}^{22}$ included lack of blinding, lack of randomization, and in general, failure to measure potential confounding factors (eg, hand hygiene compliance, effectiveness of cleaning by environmental services) or reported any patient-level data. Similar to previous studies, 2 more recent studies also demonstrated significant reductions of microbial contamination on copper-coated surfaces compared to control surfaces of 1 - to $2-\log _{10} \cdot{ }^{27,28}$

In addition, 3 clinical trials have been published in the English literature that assessed the effectiveness of coopercoated surfaces to reduce HAIs (Table 1). ${ }^{23-31}$ Of these 3 trials, 2 reported that the intervention arm (ie, copper) had a decreased incidence of HAIs, ${ }^{30,31}$ and 1 trial reported no significant reduction in HAIs. ${ }^{29}$ Importantly, none of the trials assessed the effectiveness of environmental cleaning and disinfection using fluorescent dye or ATPase measurements, and 1 did not assess compliance with hand hygiene. ${ }^{31}$ Although Salgado et $\mathrm{al}^{31}$ described their trial as a randomized clinical trial, Muller et $\mathrm{al}^{22}$ described this study as "low-quality evidence due to inappropriate randomization and lack of 
TA B LE 1. Results of Selected Clinical Trials of Copper-Coated Versus Control Surfaces to Reduce Healthcare-Associated Infections

\begin{tabular}{|c|c|c|c|c|c|c|c|c|}
\hline Author, Year & Setting & Study Design & Microbes & Coated Surfaces & $\begin{array}{l}\text { Outcomes } \\
\text { (Cu vs Control) }\end{array}$ & $\begin{array}{l}\text { Assessment } \\
\text { of HH } \\
\text { Compliance }\end{array}$ & $\begin{array}{l}\text { Assessment } \\
\text { of EVS } \\
\text { Cleaning }\end{array}$ & $\begin{array}{l}\text { Other HAI } \\
\text { Preventive } \\
\text { Initiatives }\end{array}$ \\
\hline $\begin{array}{l}\text { Von Dessauer, } \\
2016\end{array}$ & PICU, PIMCU & Quasi-experimental & All HAI & $\begin{array}{l}\text { Bed rails, bed rail } \\
\text { levers, IV poles, } \\
\text { sink handles, } \\
\text { nurses' work station }\end{array}$ & HAI (RR, $0.81 ; P=\mathrm{NS})$ & Yes & No & $\begin{array}{l}\text { Not } \\
\text { mentioned }\end{array}$ \\
\hline Sifri, 2016 & $\begin{array}{c}\text { Acute-care } \\
\text { units }\end{array}$ & $\begin{array}{l}\text { Quasi-experimental } \\
\text { (ie, before and } \\
\text { after) }\end{array}$ & MDRO, C. difficile & $\begin{array}{l}\text { Countertops (eg, sink), } \\
\text { overbed table, bed } \\
\text { rails plus } \mathrm{Cu}- \\
\text { impregnated linens }\end{array}$ & $\begin{array}{l}\mathrm{HAI}(\mathrm{RR}, 0.22 ; P=.023) \\
\quad \text { C. difficile }(\mathrm{RR}, .017 ; \\
P=.48) \\
\text { MDRO (RR, } 0.32 P=\mathrm{NS})\end{array}$ & Yes & No & Yes \\
\hline
\end{tabular}

NOTE. $\mathrm{Cu}$, copper; $\mathrm{HH}$, hand hygiene; EVS, environmental service; HAI, healthcare-associated; RR, relative risk; PICU, pediatric intensive care unit; PIMCU, pediatric intermediate care unit; IV, intravenous; NS, not significant; MRSA, methicillin-resistant Staphylococcus aureus; VRE, vancomycin-resistant Enterococcus spp; RCT, randomized clinical trial.

TABLE 2. Advantages and Limitations in the Use of Copper as a Self-Disinfecting Surface in Hospital Rooms

\section{Potential Advantages}

- Demonstrated in vitro microbicidal effectiveness including sporicidal activity

- Demonstrated ability to reduce the level and frequency of bacterial contamination on copper-coated surfaces in patient rooms

- Adverse reactions to contact with copper-coated surfaces very uncommon

- Provides continuous disinfection of copper-coated surfaces (ie, unlike ultraviolet devices and hydrogen peroxide systems, its use is not limited to terminal disinfection)

Potential Limitations and Deficiencies in the Scientific Literature

- Unclear how many and which surfaces must be coated

- Likelihood and frequency of development of reduced susceptibility to copper in healthcare-associated pathogens not well studied

- Only limited data that use of copper-coated surfaces will reduce healthcare-associated infections. Further, existing clinical trials have potential design flaws (ie, none assessed environmental cleaning effectiveness)

- Available in vitro studies and clinical trials have evaluated a variety of types of copper coatings (ie, no agreement best method to use)

- Cost of purchasing copper-coated surfaces not described in the scientific literature

- Durability of copper-coated surfaces in patient rooms poorly described

- Cost-effectiveness of using copper-coated surfaces to reduce healthcare-associated pathogens not available

blinding." An additional clinical trial has been published in the Spanish literature; it reported no differences in the frequency of nosocomial infections as well as no difference in the rates of ventilator-associated pneumonia, catheter-associated urinary tract infections, or central line-associated bloodstream infections. ${ }^{32}$ However, this study was limited by its failure to achieve its intended sample size.

The use of copper-coated surfaces to decrease contamination of hospital-room surfaces to decrease HAIs has several potential advantages over current technologies, but it also has several limitations, and several scientific questions remain unanswered (Table 2). Copper-coated surfaces have demonstrated the ability to inactivate many key pathogens associated with HAIs. Multiple studies have demonstrated that coppercoated surfaces can reduce the level of contamination on room surfaces by 1 - to $2-\log _{10}$. Importantly, unlike the "no-touch" methods that use UV devices or hydrogen peroxide systems (which currently can only be used for terminal disinfection), copper-coated surface provide continuous disinfection. To date, clinical trials have reported only rare adverse reactions related to contact with a copper-coated surface.

However, currently available studies still leave many questions regarding the routine use of copper-coated surfaces in hospital rooms. First, it is unclear how many and which surfaces must be coated to achieve a reduction in HAIs. Second, the types of copper-coating that have been studied vary, and widely accepted standard for such surfaces do not exist. Third, only a limited number of clinical trials have been published that have assessed whether copper-coated surfaces reduce the incidence of HAIs, and among published studies, copper-coated surfaces have not uniformly been shown to reduce HAIs. Furthermore, the published studies have design flaws including failure to use a randomized design and failure to account for all possible confounding variables (eg, handhygiene compliance and cleaning effectiveness). Fourth, current studies investigating microbial reductions associated 
with copper-coated surfaces or clinical outcomes (ie, reduction of HAIs) have rarely assessed whether residual microbes had intrinsic or acquired resistance to copper. Survival on copper surfaces has been described and appears to be the consequence of endospore formation, survival on patches of dirt, or a special ability to endure a dry metallic copper surface. ${ }^{23}$ The frequency and importance of reduced susceptibility to copper among healthcare-associated pathogens remains poorly defined but likely will not be clinically significant. Fifth, the cost of purchasing, installing, and maintaining coppercoated surfaces has not been delineated. Sixth, the durability of copper-coated surfaces has been poorly described. Finally, no cost-effective analysis of the use of copper-coated surfaces has been published.

In conclusion, the use of copper-coated surfaces to provide continuous room disinfection is promising, but additional carefully designed and appropriately powered studies are required before this technology should be routinely adopted to prevent HAIs.

\section{A C KNOW LEDGMENTS}

Potential conflicts of interest: J.A.O. is a consultant to Gama Healthcare. D.J.W. and W.A.R. are consultants for PDI Healthcare.

Financial support: J.A.O. would like to acknowledge support from the National Institute for Health Research Health Protection Research Unit (NIHR HPRU) in Healthcare-Associated Infection and Antimicrobial Resistance at Imperial College London in partnership with Public Health England (PHE), and the Imperial College Healthcare Trust NIHR Biomedical Research Centre (BRC).

Address correspondence to David J. Weber, MD, MPH, 2163 Bioinformatics, CB \#7030, Chapel Hill, NC, 27599-7030 (dweber@unch.unc.edu).

\section{REFERENCES}

1. Magill SS, Edwards JR, Bamberg W, et al. Multistate pointprevalence survey of health care-associated infections. $N$ Engl J Med 2014;370:1198-1220.

2. Weinstein RA. Epidemiology and control of nosocomial infections in adult intensive care units. Am J Med 1991;91: S179-S184.

3. Boyce JM. Environmental contamination makes an important contribution to hospital infection. J Hosp Infect 2007;65(Suppl 2):50-54.

4. Weber DJ, Rutala WA, Miller MB, Huslage K, Sickbert-Bennett E. Role of hospital surfaces in the transmission of emerging health care-associated pathogens: norovirus, Clostridium difficile, and Acinetobacter species. Am J Infect Control 2010;38(5 Suppl 1):S25-S33.

5. Weber DJ, Anderson D, Rutala WA. The role of the surface environment in healthcare-associated infections. Curr Opin Infect Dis 2013;26:338-344.

6. Otter JA, Yezli S, Salkeld JA, French GL. Evidence that contaminated surfaces contribute to the transmission of hospital pathogens and an overview of strategies to address contaminated surfaces in hospital settings. Am J Infect Control 2013;41(5 Suppl):S6-S11.

7. Carling PC. Optimizing health care environmental hygiene. Infect Dis Clin North Am 2016;30:639-660.

8. Donskey CJ. Does improving surface cleaning and disinfection reduce health care-associated infections? Am J Infect Control 2013;41(5 Suppl):S12-S19.
9. Otter JA, Yezli S, Perl TM, Barbut F, French GL. The role of 'no-touch' automated room disinfection systems in infection prevention and control. J Hosp Infect 2013;83:1-13.

10. Doll M, Morgan DJ, Anderson D, Bearman G. Touchless technologies for decontamination in the hospital: a review of hydrogen peroxide and UV devices. Curr Infect Dis Rep 2015; 17:498.

11. Rutala WA, Weber DJ. Disinfection and sterilization in health care facilities: an overview and current Issues. Infect Dis Clin North Am 2016;30:609-637.

12. Weber DJ, Kanamori H, Rutala WA. 'No touch' technologies for environmental decontamination: focus on ultraviolet devices and hydrogen peroxide systems. Curr Opin Infect Dis 2016;29: 424-433.

13. Weber DJ, Rutala WA, Anderson DJ, Chen LF, Sickbert-Bennett EE, Boyce JM. Effectiveness of ultraviolet devices and hydrogen peroxide systems for terminal room decontamination: focus on clinical trials. Am J Infect Control 2016;44(5 Suppl):e77-e84.

14. Boyce JM. Modern technologies for improving cleaning and disinfection of environmental surfaces in hospitals. Antimicrob Resist Infect Control 2016;5:10.

15. Boyce JM, Havill NL, Otter JA, et al. Impact of hydrogen peroxide vapor room decontamination on Clostridium difficile environmental contamination and transmission in a healthcare setting. Infect Control Hosp Epidemiol 2008;29(8):723-729.

16. Vianna PG, Dale CR Jr, Simmons S, Stibich M, Licitra CM. Impact of pulsed xenon ultraviolet light on hospital-acquired infection rates in a community hospital. Am J Infect Control 2016;44:299-303.

17. Pegues DA, Han J, Gilmar C, McDonnell B, Gaynes S. Impact of ultraviolet germicidal irradiation for no-touch terminal room disinfection on Clostridium difficile infection incidence among hematology-oncology -patients. Infect Control Hosp Epidemiol 2017;38:39-44.

18. Anderson DJ, Chen LF, Weber DJ, et al. Enhanced terminal room disinfection and acquisition and infection caused by multidrugresistant organisms and Clostridium difficile (the Benefits of Enhanced Terminal Room Disinfection study): a cluster-randomised, multicentre, crossover study. Lancet 2017;389:805-881.

19. Kundrapu S, Sunkesula V, Jury LA, Sitzlar BM, Donskey CJ. Daily disinfection of high-touch surfaces in isolation rooms to reduce contamination of healthcare workers' hands. Infect Control Hosp Epidemiol 2012;33:1039-1042.

20. Weber DJ, Rutala WA. Self-disinfecting surfaces: review of current methodologies and future prospects. Am J Infect Control 2013;41(5 Suppl):S31-S35.

21. Humphreys H. Self-disinfecting and microbiocide-impregnated surfaces and fabrics: What potential in interrupting the spread of healthcare-associated infection? Clin Infect Dis 2014;58:848-853.

22. Muller MP, MacDougall C, Lim M. Antimicrobial surfaces to prevent healthcare-associated infections: a systematic review. J Hosp Infect 2016;92:7-13.

23. Grass G, Rensing C, Solioz M. Metallic copper as an antimicrobial surface. Appl Environ Microbiol 2011;77:1541-1547.

24. Weaver L, Michels HT, Keevil CW. Survival of Clostridium diffcile on copper and steel: futuristic options for hospital hygiene. J Hosp Infect 2008;68:145-151.

25. Souli M, Antoniadou A, Katsarolis I, et al. Reduction of environmental contamination with multidrug-resistant bacteria by 
copper-alloy coating of surfaces in a highly endemic setting. Infect Control Hosp Epidemiol 2017;38:765-771.

26. O'Gorman J, Humphreys H. Application of copper to prevent and control infection. Where are we now? J Hosp Infect 2012; 81:217-223.

27. Hinsa-Leasure SM, Nartey Q, Vaverka J, Schmidt MG. Copper alloy surfaces sustain terminal cleaning levels in a rural hospital. Am J Infect Control 2016;44:e195-e20.

28. Schmidt MG, von Dessauer B, Benavente C, et al. Copper surfaces are associated with significantly lower concentrations of bacteria on selected surfaces within a pediatric intensive care unit. Am J Infect Control 2016;44:203-209.

29. von Dessauer B, Navarrete MS, Benadof D, Benavente C, Schmidt MG. Potential effectiveness of copper surfaces in reducing health care-associated infection rates in a pediatric intensive and intermediate care unit: a nonrandomized controlled trial. Am J Infect Control 2016;44:e133-e139.

30. Sifri CD, Burke GH, Enfield KB. Reduced health care-associated infections in an acute care community hospital using a combination of self-disinfecting copper-impregnated composite hard surfaces and linens. Am J Infect Control 2016;44: 1565-1571.

31. Salgado CD, Sepkowitz KA, John JF, et al. Copper surfaces reduce the rate of healthcare-acquired infections in the intensive care unit. Infect Control Hosp Epidemiol 2013;34: 479-486.

32. Rivero P, Brenner P, Nercelles P. Impact of copper in the reduction of hospital-acquired infections, mortality and antimicrobial costs in the Adult Intensive Care Unit. [In Spanish]. Rev Chilena Infectol 2014;31:274-279. 